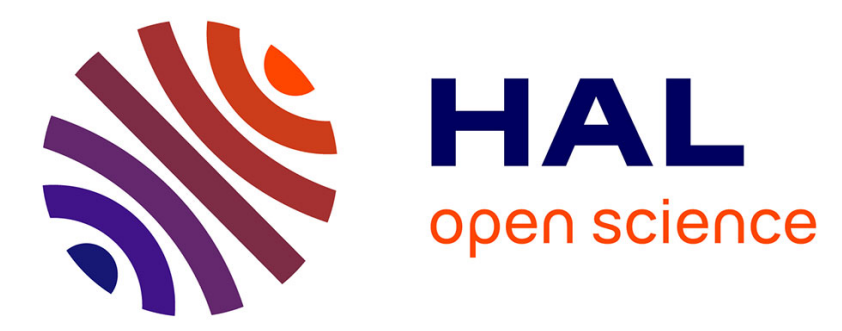

\title{
Optimal sampling times for a drug and its metabolite using SIMCYP(®) simulations as prior information.
}

Cyrielle Dumont, France Mentré, Clare Gaynor, Karl Brendel, Charlotte

Gesson, Marylore Chenel

\section{To cite this version:}

Cyrielle Dumont, France Mentré, Clare Gaynor, Karl Brendel, Charlotte Gesson, et al.. Optimal sampling times for a drug and its metabolite using SIMCYP(®) simulations as prior information.. Clinical Pharmacokinetics, 2013, 52 (1), pp.43-57. 10.1007/s40262-012-0022-9 . inserm-00769804

\section{HAL Id: inserm-00769804 https://www.hal.inserm.fr/inserm-00769804}

Submitted on 5 Dec 2013

HAL is a multi-disciplinary open access archive for the deposit and dissemination of scientific research documents, whether they are published or not. The documents may come from teaching and research institutions in France or abroad, or from public or private research centers.
L'archive ouverte pluridisciplinaire HAL, est destinée au dépôt et à la diffusion de documents scientifiques de niveau recherche, publiés ou non, émanant des établissements d'enseignement et de recherche français ou étrangers, des laboratoires publics ou privés. 
Optimal Sampling Times for a Drug and its Metabolite using SIMCYP ${ }^{\circledR}$ Simulations as Prior Information

Cyrielle Dumont ${ }^{1,2,3}$, France Mentré ${ }^{2,3}$, Clare Gaynor ${ }^{1}$, Karl Brendel ${ }^{1}$, Charlotte Gesson ${ }^{1}$, Marylore Chenel $^{1}$

1 Division of Clinical Pharmacokinetics, Institut de Recherches Internationales Servier, Suresnes, France

2 Univ Paris Diderot, Sorbonne Paris Cité, UMR 738, F-75018 Paris, France

3 INSERM, UMR 738, F-75018 Paris, France

Corresponding author: Cyrielle Dumont, Univ Paris Diderot, INSERM, UMR 738, 16 rue Henri Huchard, F-75018 Paris, France

E-mail: cyrielle.dumont@inserm.fr 


\begin{abstract}
Background: Since 2007, it is mandatory for the pharmaceutical companies to submit a Paediatric Investigation Plan to the Paediatric Committee at the European Medicines Agency for any drug in development in adults, and it often leads to the need to conduct a pharmacokinetic study in children. Pharmacokinetic studies in children raise ethical and methodological issues. Because of limitation of sampling times, appropriate methods, such as the population approach, are necessary for analysis of the pharmacokinetic data. The choice of the pharmacokinetic sampling design has an important impact on the precision of population parameter estimates. Approaches for design evaluation and optimization based on the evaluation of the Fisher information matrix $\left(\mathrm{M}_{\mathrm{F}}\right)$ have been proposed and are now implemented in several software packages, such as PFIM in R.
\end{abstract}

Objectives: The objectives of this work were to (i) develop a joint population pharmacokinetic model to describe the pharmacokinetic characteristics of a drug $\mathrm{S}$ and its active metabolite in children after intravenous drug administration from simulated plasma concentration-time data produced using physiologically based pharmacokinetic (PBPK) predictions; (ii) optimize the pharmacokinetic sampling times for an upcoming clinical study using a multi-response design approach, considering clinical constraints; and iii) evaluate the resulting design taking data below the lower limit of quantification (BLQ) into account.

Methods: Plasma concentration-time profiles were simulated in children using a PBPK model previously developed with the software SIMCYP $^{\circledR}$ for the parent drug and its active metabolite. Data were analysed using non-linear mixed-effect models with the software NONMEM $^{\circledR}$, using a joint model for the parent drug and its metabolite. The population pharmacokinetic design, for the future study in 82 children from 2 to 18 years old, each receiving a single dose of the drug, was then optimized using PFIM, assuming identical times for parent and metabolite concentration measurements and considering clinical constraints. Design evaluation was based on the relative standard errors (RSEs) of the parameters of interest. In the final evaluation of the proposed design, an approach was used to assess the possible effect of BLQ concentrations on the design efficiency. This approach consists of rescaling the $\mathrm{M}_{\mathrm{F}}$, using, at each sampling time, the probability of observing a concentration BLQ computed from Monte-Carlo simulations.

Results: A joint pharmacokinetic model with three compartments for the parent drug and one for its active metabolite, with random effects on four parameters, was used to fit the simulated PBPK concentration-time data. A combined error model best described the residual variability. Parameters and dose were expressed per kilogram of bodyweight. Reaching a compromise between PFIM results and clinical constraints, the optimal design was composed of four samples at $0.1,1.8,5$ and $10 \mathrm{~h}$ after drug injection. This design predicted RSE lower than $30 \%$ for the four parameters of interest. For this design, rescaling $\mathrm{M}_{\mathrm{F}}$ for BLQ data had very little influence on predicted RSE.

Conclusion: PFIM was a useful tool to find an optimal sampling design in children, considering clinical constraints. Even if it was not forecasted initially by the investigators, this approach showed that it was really necessary to include a late sampling time for all children. Moreover, we described an approach to evaluate designs assuming expected proportions of BLQ data are omitted. 


\section{Introduction}

New legislation governing the development and authorization of medicines for use in children was introduced in the European Union (EU) in January 2007. ${ }^{[1]}$ This piece of legislation introduced sweeping changes into the regulatory environment for paediatric medicines, designed to better protect the health of children in the EU. Thus, a Paediatric Committee was set up within the European Medicines Agency (EMA) to provide objective scientific opinions on any development plan for the use of medicines in children, and the Paediatric Investigation Plan (PIP) ${ }^{[2]}$ was introduced to the legal framework concerning medicinal products for human use. This PIP aims at ensuring that the development of medicinal products that are potentially to be used for the paediatric population becomes an integral part of the development of medicinal products, incorporated into the development programme for adults. Indeed, this measure was taken because most drugs have not been developed and assessed specifically for paediatric use and therefore they are administered to children outside the terms of their product licence. According to the EU, 50-90\% of drugs used in children have never been actually studied in this population, which can lead to the risks of adverse drug events or to a lack of efficacy. ${ }^{[3]}$

Guidances have been established to guide paediatric drug development; one is specifically dedicated to pharmacokinetic studies in children. ${ }^{[2]}$ This guideline provides advice on the use of pharmacokinetic studies in paediatric drug development and on methodological issues concerning pharmacokinetic studies in paediatric patients. Indeed, pharmacokinetic studies in children are often more difficult to perform than those in adults. Firstly, for ethical reasons, pharmacokinetic studies in children are conducted in patients who may potentially benefit from the treatment, and not in healthy volunteers, as for adults. Secondly, the blood volume that can be taken in children is much more limited than in adult healthy volunteers. As, most of the time, only sparse data can be obtained in children, population pharmacokinetic analysis using non-linear mixed-effect models is an appropriate methodology for analysing pharmacokinetic information in paediatric trials both from a practical and ethical point of view. ${ }^{[4,5,6]}$

The design of pharmacokinetic studies is really of importance when the number of samples and subjects is limited, as every sample must be informative, especially when clinical constraints are strong. Indeed, the design has a large impact on the precision of population parameter estimates. ${ }^{[7]} \mathrm{A}$ population pharmacokinetic design consists of a set of elementary designs to be carried out in a set of individuals. Elementary designs are composed of several sampling times to be drawn for each individual. In the EMA guideline related to pharmacokinetic studies in the paediatric population, simulations or theoretical optimal design approaches, based on prior knowledge, are presented as tools to be considered for the selection of sampling times, number of subjects and number of samples per subject. To avoid simulations, which are time consuming, designs can be evaluated using the Fisher information matrix $\left(\mathrm{M}_{\mathrm{F}}\right)$ and the optimization of its determinant. ${ }^{[8]}$ The calculation of the $\mathrm{M}_{\mathrm{F}}$ for the non-linear mixed-effects model was first developed by Mentré et al. ${ }^{[7]}$ and Retout et al. ${ }^{[9]}$ for uniresponse non-linear mixed-effects modelling and then extended to multi-response population pharmacokinetic/pharmacodynamic models ${ }^{[8,10]}$ using a first-order Taylor expansion of the population pharmacokinetic model around the random effect. ${ }^{[7,11,12]}$ The calculation of the $\mathrm{M}_{\mathrm{F}}$ for non-linear mixed-effects modelling used in population pharmacokinetics is performed in software packages, including PFIM developed in R, dedicated to design evaluation and optimization. ${ }^{[13,14]}$ PFIM evaluates and optimizes population designs in non-linear mixed-effects modelling with single and multiple responses ${ }^{[8]}$ and thus returns the expected standard errors, defined as the square roots of the diagonal 
elements of the inverse of the $\mathrm{M}_{\mathrm{F}}$, of the population parameters. To use PFIM, some prior information has to be supplied by the user such as the structural model, the statistical model and values of the parameters.

To get a priori information on a drug in children, methods as physiologically based pharmacokinetic (PBPK) models can be used. PBPK models, as implemented in the software SIMCYP $^{\circledR[15,16,17,18,19,20]}$ ( SIMCYP Limited, Sheffield, UK), allow the description of the pharmacokinetics of a substance based on a physiological reality. ${ }^{[1]}$ PBPK models are multicompartment models where compartments correspond to predefined organs and tissues of the body for which the interconnections correspond to flows (such as blood). PBPK modelling allows the integration of input parameters from different sources (e.g. in vitro experiments and in vivo studies) to predict plasma concentration-time profiles based on both physiological and mechanistic models. It also allows the integration of inter-individual variability (IIV) in both physiological and drug-related parameters to enable a realistic prediction of parameters and profiles for an entire population. PBPK modelling has recently received a renewed interest in pharmaceutical research and development. ${ }^{[22]}$ PBPK models also take the specificities linked to particular organs and to a given population, such as children, into account. Indeed, because of their physiological and mechanistic bases, PBPK models can take all the changes occurring during childhood, ${ }^{[16]}$ such as physiological age-related changes, protein binding, maturation of renal function and ontogeny of cytochrome P450 (CYP) and transporters, into account. There is more and more evidence on the value of PBPK modelling in providing reasonable estimates of pharmacokinetic parameters and drug concentration profiles for drugs in children. ${ }^{[23,24,25]}$

The main objective of the present work was to design a first dose-ranging study for a drug in paediatric development, in which pharmacokinetics will be assessed in children aged from 2 to 18 years old. Advanced tools, such as PBPK modelling, population pharmacokinetic modelling and multi-response optimal design methods, were used in order to obtain in fine informative pharmacokinetic data from this first paediatric pharmacokinetic study, for both drug $\mathrm{S}$ and its active metabolite, taking into account the clinical constraints imposed by the investigators. This work also aimed to show how design evaluation can help to support a sampling time strategy in a dose-ranging study in which the assessment of drug efficacy can be influenced by the blood sampling schedule and when the hospitalization duration is very limited. To the authors' knowledge, few applications of designing clinical trials in children are presently published. ${ }^{[5,26,27,28]}$

Using a PBPK model, previously developed and validated using clinical data observed in adults, concentration-time profiles of both the parent drug and its active metabolite were predicted in children after intravenous administration of the parent drug using the adults-to-children extrapolation tool in SIMCYP ${ }^{\circledR}$. This PBPK model in adults had been previously challenged to evaluate its capability to predict different scenarios (e.g. drug-drug interactions). For each simulated scenario, predictions were compared to observations, and when necessary the model was refined. ${ }^{[29]}$ Eventually, the model was judged adequate to perform pharmacokinetic predictions in children.

As shown by Chenel et al., ${ }^{[30]}$ simulated SIMCYP ${ }^{\circledR}$ data can be analysed by non-linear mixedeffects modelling to develop a population pharmacokinetic model and the resulting model can then be used to define optimal sampling design. Thus, a joint population pharmacokinetic model of the parent drug and its active metabolite was developed using SIMCYP $^{\circledR}$ predictions in children and then this model and its parameters were used to design the future dose-ranging study using multi-response optimal design as implemented in PFIM. 
For safety reasons, the future dose-ranging study will start with a low dose $(0.1 \mathrm{mg} / \mathrm{kg})$ of the parent drug. Therefore, the lower limit of quantification (LLQ), which represents the smallest concentration from which it is possible to give a reliable result, should also be taken into account during the design optimization. Although it is now possible to take into account data below the lower limit of quantification (BLQ) at the estimation stage in non-linear mixed-effects modelling by maximum likelihood, ${ }^{[31,32]}$ there is presently no statistically sound method to adequately take account of the possible existence of BLQ data at the design stage; usually an observation is merely discarded if the value is lower than BLQ. The present work also describes an approach that consists of rescaling the $\mathrm{M}_{\mathrm{F}}$ using the probability of LLQ, computed from Monte-Carlo simulations at each sampling time. A comparison, based on the relative standard errors (RSEs) of the parameters of interest, was then performed to evaluate the impact of BLQ data on the sampling design efficiency. A similar approach was already used to handle dropout in sample size and power calculations. ${ }^{[33,34]}$

\section{Methods}

\subsection{Physiologically Based Pharmacokinetic (PBPK) Simulations and Model Building}

\subsubsection{Study Design of the Paediatric Clinical Trial}

The upcoming paediatric clinical trial will include 82 children aged from 2 to 18 years old. Four age classes have been defined based on clinical characteristics: $[2$ to $<5]$, $[\geq 5$ to $<8]$, $[\geq 8$ to $<12$ ] and $[\geq 12$ to 18$]$ years old. Due to the low prevalence of the disease in the youngest class, only ten patients have been planned in the 2- to 5-year-old class, whereas 24 patients will be included in each of the three other classes.

Each child will receive a single intravenous dose of the compound in this dose-ranging paediatric clinical trial, expressed as $\mathrm{mg} / \mathrm{kg}$. The starting dose is $0.1 \mathrm{mg} / \mathrm{kg}$. Between 20 and $40 \mathrm{~min}$ after the dose injection, a clinical examination will be performed and this examination will take about $30 \mathrm{~min}$. Therefore, the period of 20-90 min (i.e. $0.3-1.5 \mathrm{~h}$ ) after dose administration will be strictly dedicated to the clinical examination (i.e. no pharmacokinetic sampling can occur during this period). To limit the risk of operational error and simplify the protocol, the same sampling time design will be performed in all four age classes. Finally, $5 \mathrm{~h}$ after dose injection, as no safety concern remains at this stage, the child will be discharged from the hospital.

\subsubsection{PBPK Simulations}

Using SIMCYP ${ }^{\circledast}$ software (version 9.00), a full PBPK model was previously developed in adults for the parent drug which was used for the prediction of the distribution (i.e. volume) (the Rodgers and Rowland method ${ }^{[35]}$ ) from the unbound fraction of the drug in plasma $\left(\mathrm{f}_{\mathrm{u}}\right)$, the unbound fraction of the drug in tissue $\left(\mathrm{f}_{\mathrm{u}, \mathrm{t}}\right)$, the partition coefficient $(\log \mathrm{P})$ and the acid dissociation constant (pKa) of the molecule. Regarding drug elimination, two CYP3A4 pathways were modelled using maximum metabolic rate/Michaelis-Menten constant obtained from experiments on microsomes, one out of the two pathways leading to the formation of the active metabolite. To take into account the renal 
elimination of the compound (about $20 \%$ of the total clearance), a renal clearance component was also added. For the active metabolite, a one-compartment model was used to describe the disposition of the compound. The values of the distribution volume and of the total elimination clearance, split into a renal and a non-renal clearances, were determined from an in vivo study in humans, who received the active metabolite intravenously. Using this PBPK model developed in adults and the adults-to-children extrapolation tool in SIMCYP ${ }^{\circledR}{ }^{[36]}$ (version 9.00), plasma concentration-time profiles were simulated for both the parent drug and its active metabolite after a $0.1 \mathrm{mg} / \mathrm{kg}$ intravenous dose (as an infusion of $30 \mathrm{~s}$ ) in 400 subjects aged from 0 (i.e. birth) to 25 years old with the same proportion of girls and boys.

The resulting dataset contained 22 observations per subject with sampling times of $0.1,0.2$, $0.4,0.6,0.8,1,1.3,1.6,1.8,2,2.5,3,4,5,6,7,8,9,10,12,16$ and $24 \mathrm{~h}$ after dose injection. Fig. 1 shows the simulated concentration-time profiles for both the parent drug and its active metabolite in the 400 subjects. Thus, the dataset for the population pharmacokinetic modelling consisted of 17,600 simulated concentration-time data points.

\subsubsection{Population Pharmacokinetic Modelling: Model Building and Parameter Estimation}

A non-linear mixed-effect model was built to jointly fit parent- and metabolite-simulated concentration-time data in children. Note that the population pharmacokinetic modelling was performed with simulated data, i.e. observations were simulated concentration-time data coming from SIMCYP $^{\circledR}$. This population pharmacokinetic analysis was performed using NONMEM $^{\circledR}$ version 7.2 software ${ }^{[37]}$ and the population pharmacokinetic model parameters were estimated by maximum likelihood with the First Order Conditional Estimation with Interaction (FOCEI) method. ${ }^{[38]}$ As the dose will be given per kilogram in the paediatric clinical trial to come, all parameters are expressed per kilogram. In order to determine the structural model, different numbers of compartments were tested for the parent drug (i.e. one, two and three compartments) and for the metabolite (i.e. one and two compartments). The distribution and elimination processes were parameterized in terms of clearances and volumes of distribution. The differences between individuals on a pharmacokinetic parameter were regarded as random quantities and were modelled in terms of random effects $(\eta)$. Each random effect was assumed to have a mean equals to zero and a variance $\left(\omega^{2}\right)$. This variance describes the IIV of the considered pharmacokinetic parameter.

The differences between the observed concentrations and the predicted concentrations were regarded as random quantities and were modelled in terms of residual errors $(\varepsilon)$. Each error was assumed to have a mean equal to zero and a variance $\left(\sigma^{2}\right)$. Additive and/or multiplicative error models were tested for the parent and for the metabolite.

Model selection was based on the comparison of the objective function given by NONMEM ${ }^{\circledR}$. Objective function is defined as minus twice the log-likelihood (up to an additive constant). For nested models, a likelihood ratio test was performed with a $p$ value of 0.05 ; i.e. the difference on objective function was compared to the limit of a chi-square distribution, with a number of degrees of freedom equal to the number of additional parameters in the full model. For non-nested models, model comparison was based on the Bayesian Information Criterion (BIC) ${ }^{[39]}$; the model with the lowest BIC was chosen. Model selection was also based on goodness-of-fit (GOF) plots (i.e. SIMCYP ${ }^{\circledR}$ data, 
called dependent variable [DV], vs. individual predictions [IPRED] and normalized prediction distribution error $[\mathrm{NPDE}]^{[40]}$ vs. time) and precision of the parameter estimates (RSE expressed as percentage). For the NPDE versus time plot, 500 replications of the original datasets composed of 400 subjects were simulated using the final model parameter estimates of the joint parent-metabolite population pharmacokinetic model.

\subsection{Optimization of the Sampling Times in the Paediatric Study}

\subsubsection{Clinical Constraints}

Following the constraints requested by the clinical investigators, the pharmacokinetic protocol was simplified and therefore the optimization was performed considering only one elementary design, i.e. one group of 82 children. The number of blood samples must be as limited as possible, ideally four samples per subject, and the duration of the hospital visit must be as short as possible, preferably up to $5 \mathrm{~h}$ after dose administration. As the clinical examination will take place between 20 and 90 min (i.e. between 0.3 and $1.5 \mathrm{~h}$ ) after dose administration, no pharmacokinetic samples can be collected over this period. Moreover, clinicians were not in favour of having pharmacokinetic samples before the clinical investigation, i.e. from the time of drug administration up to 20 min post-dose.

Identical sampling times were considered, for practical and ethical reasons, for parent and metabolite concentration measurements. As the pharmacokinetics of the parent drug and its active metabolite are expected to be linear, the evaluation of the protocol was performed with the lowest dose to be tested in the clinical protocol, i.e. $0.1 \mathrm{mg} / \mathrm{kg}$.

\subsubsection{Optimization and D-Optimality Criterion}

The optimization was performed with PFIM, which uses the D-optimality criterion. A design is considered to be D-optimal if it maximizes the determinant of $\mathrm{M}_{\mathrm{F}}$, which means it minimizes the confidence region associated with the parameter estimates.

For the optimization, the initial stage of the Federov-Wynn algorithm implemented in PFIM ${ }^{[41]}$ was used in order to have only one group of elementary designs. Parameters of interest were defined as the volume of the central compartment of the parent drug, parent drug elimination clearance, and metabolite formation and elimination clearances. For a design to be deemed satisfactory, the predicted RSE of these four fixed effects (i.e. parameters of interest) had to be lower than $30 \%$.

The optimization was performed using the population joint parent-metabolite pharmacokinetic model developed using PBPK predictions in children (see Sect. 2.1.2) and its parameter estimates. As omitting the covariance at the design stage does not influence the design efficiency (i.e. ratio of determinant $\left(\mathrm{M}_{\mathrm{F}}\right)^{1 / \mathrm{P}}$ of the compared designs, $\mathrm{P}$ being the total number of parameters $),{ }^{[42,43]}$ the design optimization was performed ignoring covariance between random effects, if any. The potential sampling times allowed were $0.1,0.2,0.4,0.6,0.8,1,1.3,1.6,1.8,2,2.5,3,4,5,6,7,8,9,10,12,16$ and $24 \mathrm{~h}$ after dose injection. 


\subsubsection{Scenarios Investigated}

To find the best compromise between the fulfilment of the clinical constraints and a satisfactory level of accuracy for parameter estimation, different scenarios were investigated.

The first scenarios tested were designs with four, five and six sampling times over $24 \mathrm{~h}$ after dose injection, among the allowed times, without any constraints. All other investigated designs did not permit any sampling time between 0.3 and $1.5 \mathrm{~h}$ after dose, as required by the clinical constraints. Other tested designs consisted of four sampling times with the last sampling time being after $5 \mathrm{~h}$ after dose injection, increasing this last time (i.e. 5, 6, 8, 10 and $24 \mathrm{~h}$ after dose) and, finally, the last investigated designs consisted of three, four and five sampling times over $5 \mathrm{~h}$ after dose injection with one additional sampling time at $10 \mathrm{~h}$ after dose injection. Investigated scenarios are summarized in Table 1.

\subsection{Approach for Considering Lower Limit of Quantification in Design}

For both the parent compound and its active metabolite, the LLQ of concentration is 0.25 $\mathrm{ng} / \mathrm{mL}$.

In Sect. 2.2, LLQ was not considered during design optimization as the simulated observations have no LLQ. Ideally, the prediction of BLQ data should be taken into account in the optimization of sampling times since collecting BLQ data leads to a loss of information at the estimation stage. Therefore, the following approach, i.e. rescaling of $\mathrm{M}_{\mathrm{F}}$ using the probability of BLQ at each sampling time, was implemented. This approach was proposed for one design ( $\Xi$ ) composed of one elementary design $(\xi)$ with $\mathrm{n}$ sampling times, applied to the 82 children.

Firstly, 1,000 Monte-Carlo simulations of concentrations at the sampling times of design $\xi$ were performed in $\mathrm{R}$ using the population pharmacokinetic model and then the proportion of BLQ data for parent or for metabolite concentrations at each of the $\mathrm{n}$ sampling times was computed from the 1,000 simulations. Sampling times that presented a proportion of BLQ data larger than $10 \%$ for parent or metabolite were further studied. We evaluated the proportion of children having BLQ concentrations at all of these sampling times, at several of these sampling times, or at only one of them. Each case corresponds to a combination.

Secondly, to rescale $\mathrm{M}_{\mathrm{F}}$ the following procedure is used, creating several elementary designs out of design $\Xi$. For each combination, an elementary design missing the corresponding sampling times was constructed. Each of these elementary designs was affected by the number of children obtained as a rounded number of the simulated proportions for 82 children, who did not have BLQ concentrations. Elementary designs having a number of children lower than 0.5 were not considered. The initial elementary design $\xi$ was then added to the population design with a number of children so that the total will be 82 . The final population design was composed of all of these elementary designs.

The initial design with all children having all pharmacokinetic sampling times was then compared to the design taking into account the BLQ data. The comparison was based on the RSE of parameters. 
Simulations were performed for a dose of $0.1 \mathrm{mg} / \mathrm{kg}$, which is the lowest dose planned in the future dose-ranging study, and therefore represented the worst-case scenario in terms of probability of having BLQ data.

\section{Results}

\subsection{Joint Parent-Metabolite Population Pharmacokinetic Model}

The structural pharmacokinetic model developed to jointly fit predicted parent and metabolite concentration-time profiles in subjects was a three-compartment model for the parent and onecompartment model for the metabolite, represented in Fig. 2. In this model, $C L_{P}$ represents the elimination clearance of the parent drug, $\mathrm{CL}_{\mathrm{PM}}$ represents the formation clearance of the metabolite from the parent drug and $\mathrm{CL}_{\mathrm{M}}$ corresponds to the elimination clearance of the metabolite. $\mathrm{V}_{1}$ and $\mathrm{V}_{4}$ represented the volume of the central compartment for the parent and the metabolite, respectively, and $\mathrm{V}_{2}$ and $\mathrm{V}_{3}$ represented the volumes of the two peripheral compartments of the parent drug. For model identifiability, the volume of the metabolite compound was fixed to the sum of the three volumes of the parent, i.e. $V_{4}=V_{1}+V_{2}+V_{3}$. $C L_{P}, C L_{P M}, C L_{M}$ and $V_{1}$ were considered to be the four parameters of interest for design optimization. Significant IIV was found on the clearances $C_{P}, C_{P M}$ and $C_{M}$, and on the volume of the central compartment of the parent $\mathrm{V}_{1}$. Moreover, these random effects were significantly correlated and a full covariance matrix was estimated for those four parameters. The residual error model was a combined error model for both the parent and the metabolite. The additive errors for the parent drug and its active metabolite were given by $\sigma_{\text {interP }}$ and $\sigma_{\text {interM }}$, respectively, and $\sigma_{\text {slopep }}$ and $\sigma_{\text {slopem }}$ denoted the proportional parts of the residual error models for the parent drug and its active metabolite, respectively.

Table 2 displays the parameter estimates with their respective RSE. The RSE values of fixed effect parameters were all lower than $30 \%$ and RSE of variance parameters $\left(\omega^{2}\right)$ were all lower than $50 \%$. Covariance parameters, except those with very small values, were well estimated. Overall, model parameters were judged to be well estimated.

Fig. 3 displays SIMCYP ${ }^{\circledR}$ data (called DV) versus IPRED and NPDE versus time for the parent drug and its active metabolite. The DV versus IPRED plot for the parent drug displayed a bias for high concentrations, while the corresponding plot for the metabolite was satisfactory. For the NPDE versus time plot of the parent drug, a bias was again observed at early times, which correspond to high concentrations, and the same trend was observed in the NPDE versus time plot of the metabolite. Overall, GOF plots were not perfect but they were deemed acceptable for the purposes of further designing the clinical study.

\subsection{Optimal Sampling Time Design of the Paediatric Clinical Pharmacokinetic Study}

The sampling time design optimization was performed using the joint parent-metabolite pharmacokinetic model presented in Sect. 3.1. PFIM allows the utilization of some inbuilt common pharmacokinetic models up to three compartments ${ }^{[4]}$ or user-written models. As the joint parent- 
metabolite model was not included in the PFIM library, the simultaneous differential equations were solved to obtain the analytical solution of the model, which was then implemented in PFIM.

Scenarios presented in Sect. 2.2.3 were investigated and compared. However, the possible existence of BLQ data was not considered.

Table 3 displays the results of the optimization of $\Xi_{4 p t s \_24 h}, \Xi_{5 \text { pts_24h }}$ and $\Xi_{6 p t s \_4 h}$; three designs allowing four, five or six sampling times, respectively, to be chosen, without any constraint, from the 22 possible times between 0.1 and $24 \mathrm{~h}$ after dose injection. As expected, optimal designs always included several sampling times after $5 \mathrm{~h}$ with, in all cases, one sampling time at $24 \mathrm{~h}$ after dose, whatever the total number of sampling times (i.e. four, five or six). For these three designs, the RSE of the parameters of interest were very close and always lower than $30 \%$. However, the RSE of some other fixed-effect parameters, such as inter-compartmental clearance $\left(\mathrm{Q}_{2}\right)$ and $\mathrm{V}_{2}$, were not satisfactory, particularly when the number of allowed sampling times is very limited. Regarding the variance parameters or the error model parameters, the RSE were close for the three designs and lower than $30 \%$.

Table 4 shows the comparison of the RSE between the designs $\Xi_{4 \mathrm{pts} \_5 \mathrm{~h}}, \Xi_{3 \mathrm{pts} \_ \text {h__lpt_6h }}$,

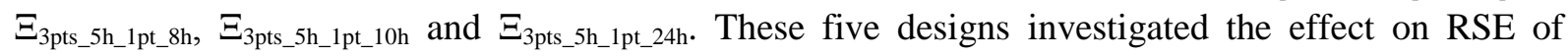
having one sampling time after $5 \mathrm{~h}$ post-dose (at 6, 8, 10 and $24 \mathrm{~h}$ ). Each of these five designs had a total of four sampling times and did not allow any sampling between 20 and 90 min post-dose to respect the clinical examination period. RSE values were very high for the two designs, with latest sampling times at 5 or $6 \mathrm{~h}$ after dose injection. Having three sampling times up to $5 \mathrm{~h}$ and one additional time at $8 \mathrm{~h}$ post-dose improved the parameter estimate precision but RSE values were still greater than $30 \%$ for $\mathrm{CL}_{\mathrm{PM}}$ and $\mathrm{CL}_{\mathrm{M}}$. Therefore, it was necessary to have a sampling time at least at $10 \mathrm{~h}$ after dose injection to obtain acceptable RSE for the four parameters of interest. There was little

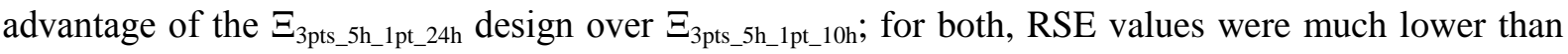
$30 \%$ for the four parameters of interest. Therefore, the chosen design was $\Xi_{3 \mathrm{pts} \_ \text {h__ } 1 \text { pt_10h }}$ with sampling times at $0.1,1.8,5$ and $10 \mathrm{~h}$ after dose injection.

The influence of increasing the number of sampling times before $5 \mathrm{~h}$ was also investigated. Table 5 shows the results obtained for designs with three, four and five sampling times up to $5 \mathrm{~h}$ and always one additional time at $10 \mathrm{~h}$ after dose injection. Increasing the number of sampling times before $5 \mathrm{~h}$ had only a very low impact on the RSE of the four parameters of interest. Fig. 4 displays the gain or the loss of efficiency of each design compared to the chosen design $\Xi_{3 \mathrm{pts} \_ \text {h__1pt_10h }}$.

\subsection{Handling Limit of Quantification in Design Evaluation}

To assess the impact of BLQ data, two designs were chosen: the one proposed to the investigators $\left(\Xi_{\text {3pts_5h_1pt_10h }}\right)$ and the one with a later sampling time at $24 \mathrm{~h}\left(\Xi_{\text {3pts_5h_1pt_24h }}\right)$.Table 6 illustrates the proportion of children, with BLQ concentrations for the parent drug and its active metabolite, at each sampling time of these two designs. For design $\Xi_{3 \mathrm{pts} \_ \text {h__1pt_10h }}$, the proportion of children with BLQ concentrations was negligible at all times for the parent drug, whereas $34 \%$ and 33 $\%$ of the children had metabolite BLQ concentrations at 0.1 and $10 \mathrm{~h}$ after dose injection, respectively; the proportions of children with metabolite BLQ concentrations at 1.8 and $5 \mathrm{~h}$ after dose injection were negligible. Percentages of children having parent and metabolite BLQ concentrations at $24 \mathrm{~h}$ after dose injection were very high: 75 and $92 \%$, respectively. Regarding the design $\Xi_{3 \mathrm{pts} \_ \text {h__1pt_10h }}$, the 
simulation results showed that $19 \%$ of children presented concentrations BLQ at both 0.1 and $10 \mathrm{~h}, 15$ $\%$ at $0.1 \mathrm{~h}$ only and $14 \%$ at $10 \mathrm{~h}$ only. Therefore, to evaluate $\mathrm{M}_{\mathrm{F}}$ by rescaling, a design with four measurable parent concentrations (i.e. at $0.1,1.8,5$ and $10 \mathrm{~h}$ after dose) in all children, and with 16 children (i.e. $19 \%$ of 82) with measurable metabolite concentrations at only 1.8 and 5 h, 12 children (i.e. $15 \%$ of 82) with measurable metabolite concentrations at only $1.8,5$ and $10 \mathrm{~h}, 11$ children (i.e. 14 $\%$ of 82 ) with measurable metabolite concentrations at only $0.1,1.8$ and $5 \mathrm{~h}$, and the remaining 43 children with measurable metabolite concentrations at all sampling times, was evaluated. A similar approach was performed for the $\Xi_{3 p t s \_5 h_{1} 1 p t \_24 h}$ design. As the proportion of BLQ concentrations was considered non-negligible for the parent compound at $24 \mathrm{~h}$ and for the metabolite at 0.1 and $24 \mathrm{~h}$, the design evaluation was performed considering eight different elementary designs. Since the mean predicted concentration was BLQ at $24 \mathrm{~h}$, only a few children have a useful sample at $24 \mathrm{~h}$. To evaluate $\mathrm{M}_{\mathrm{F}}$ by rescaling, a design with 41 children (i.e. $50 \%$ of 82 ) with measurable concentrations at $0.1,1.8$ and $5 \mathrm{~h}$ for both parent and metabolite, 17 children (i.e. $21 \%$ of 82) with measurable concentrations at $0.1,1.8$ and $5 \mathrm{~h}$ for the parent and 1.8 and $5 \mathrm{~h}$ for the metabolite, ten children (i.e. 12 $\%$ of 82) with four measurable parent concentrations and with measurable metabolite concentrations at only 1.8 and $5 \mathrm{~h}$, seven children (i.e. $9 \%$ of 82 ) with measurable concentrations at all time points, except at $24 \mathrm{~h}$ for the metabolite, three children (i.e. $4 \%$ of 82) with all measurable concentrations, except at $24 \mathrm{~h}$ for the parent, one child (i.e. $1 \%$ of 82 ) with measurable concentrations at all time points, except at $0.1 \mathrm{~h}$ for the metabolite, and the remaining three children with measurable both parent and metabolite concentrations at all sampling times, was evaluated. The combination with BLQ concentrations at $24 \mathrm{~h}$ for the parent and $0.1 \mathrm{~h}$ for the metabolite was negligible. Fig. 5 illustrates the comparison, in terms of precision of parameter estimation, between the case where the proportions of children with BLQ concentrations are taken into account and the case where this information is not considered, for both the $\Xi_{3 p t s 5 \text { h__1pt_10h }}$ and $\Xi_{3 p t s \_5 h_{-} 1 \text { pt_24h }}$ designs. As expected, the RSE values of the design taking the proportion of BLQ data into account were slightly higher than those of the design that considered all concentrations as measurable (i.e. informative). However, in this example, the impact of BLQ data was not important and overall RSE values were still satisfactory when BLQ data were considered.

\section{Discussion}

The objective of this work was to optimize the pharmacokinetic sampling time design in a first dose-ranging study in children for a drug in paediatric development. The first step was to simulate plasma concentration-time profiles using PBPK predictions to obtain data in children. The adult-tochildren extrapolation tool in SIMCYP ${ }^{\circledR}$ was used in its default setting, and therefore predicted pharmacokinetic profiles were obtained in a population of 0 - to 25 -year-old subjects. The next step was to build a joint parent-metabolite pharmacokinetic model to fit the PBPK predicted concentration-time profiles after intravenous drug administration in children. The structural pharmacokinetic model developed for the parent drug and its metabolite was a four-compartment model (i.e. three compartments for the parent drug and one compartment for the metabolite) with a combined residual error model. Moreover, IIV was estimated on four parameters, i.e. the parent drug elimination clearance, the metabolite formation and elimination clearances, and the central compartment volume of the parent drug. The corresponding random effects were correlated. As the doses will be given in milligrams per kilogram in the upcoming paediatric clinical trial, the dose and the model parameters were expressed per kilogram. The population parameters of the model were well 
estimated (with small RSE), except for some covariance parameters when they were very small. As a waiver has been obtained for the group of children aged between 0 and 2 years old, population pharmacokinetic parameters obtained in using the whole dataset (0- to 25-year-old subjects) or a reduced dataset, i.e. only subjects between 2 and 18 years old, were compared at the end of the present work when the final decision for the waiver was obtained. No difference was noticed between the two sets of parameter estimates that could have changed the results of the present work.

The sampling time design was then optimized from the joint parent-metabolite pharmacokinetic model. As omitting the covariance at the design stage does not affect the design efficiency, ${ }^{[42,43]}$ the design optimization was performed ignoring covariance between random effects. Even though PFIM allows the optimization of different sampling times for two responses, the multiresponse optimization was carried out assuming the same sampling times for the parent drug and its active metabolite in order to limit the total number of sampling times. Design optimization was performed in 82 children considering the constraints of the clinical trial such as the number of groups with different elementary designs (i.e. only one group here), the restrictions on some sampling times and the duration of stay at the hospital. Different designs were tested with various numbers of sampling times, with or without a late time (i.e. after $5 \mathrm{~h}$ ). Comparison of designs was based on the RSE of four parameters judged to be the parameters of interest. Distant stochastic (DS)-optimality could have been used but it is not yet implemented in PFIM. In addition, DS-optimality does not take estimation of all parameters into account and can lead to design with poor identifiability. ${ }^{[45]}$ Evaluation of protocol should theoretically be based on both precision and accuracy of the estimated parameters. This refers to X-optimality. ${ }^{[46]}$ However, in non-linear mixed-effect modelling it is assumed that estimation methods are unbiased although this is true only asymptotically. All currently available software tools for evaluation/optimization of designs in non-linear mixed-effects models are based on the $\mathrm{M}_{\mathrm{F}}$ and on the reduction of estimation variance. ${ }^{[47]}$ This is a current limitation of this approach.

Taking the practical constraints requested by clinicians into account, the best compromise resulted in a design with three samples before $5 \mathrm{~h}$ post-dose, no sampling between 20 and $90 \mathrm{~min}$ and one sampling time at $10 \mathrm{~h}$. These optimized sampling times were $0.1,1.8,5$ and $10 \mathrm{~h}$ after drug administration in all children. The necessity of a late sampling time such as $10 \mathrm{~h}$ post-dose was obvious when looking at the RSE values (Table 4). The results predicted by this approach were very helpful in convincing the clinicians to pursue the investigation later than $5 \mathrm{~h}$. Therefore, it was decided to propose the fourth time at $10 \mathrm{~h}$ for all children and, if the parents refuse to spend more time at the hospital, the fourth sample will be collected $5 \mathrm{~h}$ post-dose, just before the child is discharged. This optimized design was implemented in the clinical protocol and it was proposed to re-evaluate it after inclusion of the first 20 children participating. This design is anticipated to analyse pharmacokinetic data in children in estimating only the parameters of interest, or to reduce the population pharmacokinetic model (i.e. simplification with compartment lumping ${ }^{[48]}$ ).

In the present work, simulated data were used to build the joint parent-metabolite population pharmacokinetic model and, therefore, there was no need to handle BLQ data as it is predicted via a model (in the present case, concentrations below $0.25 \mathrm{ng} / \mathrm{mL}$ ). However, when observed data in children are available, BLQ data will be flagged as usual and it will be necessary to handle these data. As, the probability of having BLQ observations was not taken into account during the optimization in PFIM, designs were also evaluated when BLQ data are omitted. To assume that the BLQ data are omitted constitutes a lower bound for $\mathrm{M}_{\mathrm{F}}$ because, in fact, it is a piece of information that is now taken into account in estimation. In the present work, no major differences were observed with and without considering LLQ for both the $\Xi_{3 \text { pts_5h_1pt_10h }}$ and $\Xi_{3 p t s \_5 h_{-} 1 \mathrm{pt} \_24 \mathrm{~h}}$ designs. However, there are cases for 
which larger differences are anticipated. It is interesting to notice that RSE corresponding to the $\Xi_{\text {3pt__5 _1pt_24h }}$ design, which takes BLQ into account, are lower than the RSE corresponding to the $\Xi_{3 p t s \text { 5h_1pt_10h }}$ design, although there are a large number of BLQ data at $24 \mathrm{~h}$, particularly for the metabolite (Fig. 5). This can be partly explained by the fact that the metabolite elimination is formation rate limited. Of note, the mean predicted concentration at $24 \mathrm{~h}$ is BLQ for both parent and metabolite, and the 'standard' approach of ignoring these points would be misleading in this case. Expression of the $\mathrm{M}_{\mathrm{F}}$ for non-linear mixed-effects modelling with observed and left-censored data is not yet available and future developments are needed.

Of note, a comparison of the proportion of children having BLQ concentrations for the parent drug and its active metabolite (i.e. predicted concentration below $0.25 \mathrm{ng} / \mathrm{mL}$ ) at the sampling times proposed in the study to come has been made between the predictions obtained by the adult-tochildren extrapolation tool in SIMCYP ${ }^{\circledR}$ and the proportions obtained in $\mathrm{R}$ using the population pharmacokinetic model developed in NONMEM $^{\circledR}$. As expected, similar proportions have been obtained; this gives some reassurance in the joint population pharmacokinetic model developed.

A limitation of optimal design for non-linear mixed-effects modelling is that the results depend upon the parameters of the population pharmacokinetic model. Therefore, an a priori value of the population characteristics should be given. Here, study data were simulated plasma concentration versus time profiles coming from the SIMCYP ${ }^{\circledR}$ software rather than real data. This can be considered as a limitation of this example because the simulated data were fitted and the parameter estimates were considered to be the true parameters of the pharmacokinetic model in children. Moreover, the structural model, the error model and the random-effects model were assumed to be known. No sensitivity analysis with respect to model misspecification and/or misspecification of parameter values was performed in the present work. However, it was proposed that the optimized design be reevaluated after inclusion of the first 20 children. This is not a formal adaptive design ${ }^{[49]}$ and future statistical developments are needed.

As no pharmacokinetic data were available in children at the time of the protocol writing, it was considered preferable to have predicted PBPK data rather than to consider adult parameters and to divide them by kilograms, as is usually done. The combination of allometric scaling and a maturation function, ${ }^{[6]}$ on the one hand, and PBPK, on the other hand, are not always interchangeable. ${ }^{[50]}$ But predictions performed from PBPK models are more accurate than predictions performed from allometric scaling, ${ }^{[20,21,22]}$ although this is still an extrapolation to children.

PBPK simulations obtained with SIMCYP ${ }^{\circledR}$ did not include any random error to mimic measurement errors. Although the joint population pharmacokinetic model included two combined residual error models, one by compound, to account for the residual errors, as expected, the sizes of these residual errors were relatively low (i.e. proportional parts were lower than $20 \%$ and additive parts were below half of the LLQ). The size of the residual error has an impact on the accuracy of estimation (i.e. as the size of the residual error increases, accuracy of estimation decreases) and can also have an impact on the optimal sampling times. In the present work, considering a model with the proportional parts equal to $20 \%$ for both compounds and additive parts fixed at half of the LLQ, i.e. considering a worse scenario that is not likely to happen in the well-controlled study to come, leads to an increase of the RSE of the parameters of interest. Nevertheless, the RSEs are lower than $60 \%$. However, the authors strongly recommend testing the sensitivity to changes in residual errors when using such an approach. 


\section{Conclusions}

This work showed an approach to design a first pharmacokinetic study in children for a drug in paediatric development, using data generated by PBPK (SIMCYP ${ }^{\circledR}$ ) and using PFIM to optimize the pharmacokinetic sampling times. PFIM was a useful tool for finding an optimal design, particularly as the amount of time available to design the study was limited and these results could not have been obtained in such a timely manner through simulations. Moreover, PFIM is also particularly useful when the design constraints are strong (for instance, when pharmacokinetic sampling can perturb a clinical examination or when hospitalization duration is limited) and it allows a justification to be provided for each sampling time. Showing the impact of not having a late sampling time on pharmacokinetic parameter estimation was useful to convince the clinical investigators to collect a sample from each child at $10 \mathrm{~h}$ after dose injection; without such a tool, this would not have been possible. Thus, the design proposed was the best compromise between a satisfactory level of parameter estimation accuracy for subsequent population pharmacokinetic analysis and the study feasibility and children wellness. Indeed, although having a late sampling time at $24 \mathrm{~h}$ leads to an improvement in the parameter estimation, this design was not selected because the improvement in parameter estimation accuracy was not judged to be enough in comparison to the difficulty of implementing such a late sampling time in the clinical trial and the discomfort of the children. 


\section{References}

1. B Regulation (EC) no 1901/2006 of the European Parliament and of the Council of 12 December 2006 on medicinal products for paediatric use and amending Regulation (EEC) no 1768/92, Directive 2001/20/EC, Directive 2001/83/EC and Regulation (EC) No 726/2004. http://eurlex.europa.eu/LexUriServ/site/en/consleg/2006/R/02006R1901-20070126-en.pdf. Accessed 2012 Nov 5

2. Committee for Medicinal Products for Human Use (CHMP). Guideline on the role of pharmacokinetics in the development of medicinal products in the paediatric population. London, 28 June 2006. Doc. Ref. EMEA/CHMP/EWP/147013/2004. Corrigendum. http://www.ema.europa.eu/docs/en_GB/document_library/Scientific_guideline/2009/09/WC5000 03066.pdf. Accessed 2012 Nov 5

3. Bouzom F, Walther B. Pharmacokinetic predictions in children by using the physiologically based pharmacokinetic modelling. Fundam Clin Pharmacol 2008; 22: 579-87

4. Committee for Medicinal Products for Human Use (CHMP). Guideline on the role of pharmacokinetics in the development of medicinal products in the paediatric population. London, 28 June 2006. Doc. Ref. EMEA/CHMP/EWP/147013/2004. Corrigendum. http://www.tga.gov.au/pdf/euguide/ewp14701304en.pdf. Accessed

5. Mentré F, Dubruc C, Thénot JP. Population pharmacokinetic analysis and optimization of the experimental design for mizolastine solution in children. J Pharmacokinet Pharmacodyn 2001; 28:299-319

6. Tod M, Jullien V, Pons G. Facilitation of drug evaluation in children by population methods and modelling. Clin Pharmacokinet 2008; 47: 231-43

7. Mentré F, Mallet A, Baccar D. Optimal design in random-effects regression models. Biometrika 1997; 84: 429-42

8. Bazzoli C, Retout S, Mentré F. Fisher information matrix for nonlinear mixed effects multiple response models: evaluation of the appropriateness of the first order linearization using a pharmacokinetic/pharmacodynamic model. Stat Med 2009; 28: 1940-56

9. Retout S, Mentré F, Bruno R. Fisher information matrix for non-linear mixed-effects models: evaluation and application for optimal design of enoxaparin population pharmacokinetics. Stat Med 2002; 21: 2623-39

10. Gueorguieva I, Ogungbenro K, Graham G, et al. A program for individual and population optimal design for univariate and multivariate response pharmacokinetic and pharmacodynamic models. Comput Methods Programs Biomed 2007;86: 51-61

11. Mentré F, Burtin Y, Merlé Y, et al. Sparse-sampling optimal designs in pharmacokinetics and toxicokinetics. Drug Inf J 1995; 29: 997-1019

12. Retout S, Duffull S, Mentré F. Development and implementation of the population Fisher information matrix for evaluation of population pharmacokinetic designs. Comput Methods Programs Biomed 2001; 65: 141-51 
13. PFIM. http://www.pfim.biostat.fr. Accessed 2012 Nov 5

14. Bazzoli C, Retout S, Mentré F. Design evaluation and optimisation in multiple response nonlinear mixed effects models: PFIM 3.0. Comput Methods Programs Biomed 2010; 98: 55-65

15. Jamei M, Marciniak S, Feng K, et al. The Simcyp population-based ADME simulator. Expert Opin Drug MetabToxicol2009; 5: 211-23

16. Johnson TN, Rostami-Hodjegan A, Tucker G.T. Prediction of the clearance of eleven drugs and associated variability in neonates, infants and children. Clin Pharmacokinet 2006; 45: 931-56

17. Johnson TN, Rostami-Hodjegan A. Resurgence in the use of physiologically based pharmacokinetic models in pediatric clinical pharmacology: parallel shift in incorporating the knowledge of biological elements and increased applicability to drug development and clinical practice. Pediatr Anesth 2011; 21: 291-301

18. Rostami-Hodjega A, Tucker GT. Simulation and prediction of in vivo drug metabolism in human populations from in vitro data. Nat Rev Drug Discov 2007; 6: 140-48

19. Rowland M, Peck C, Tucker G. Physiologically-based pharmacokinetics in drug development and regulatory science. Annu Rev Pharmacol Toxicol 2011; 51: 45-73

20. Zhao P, Zhang L, Grillo JA, et al. Applications of physiologically based pharmacokinetic (PBPK) modeling and simulation during regulatory review. Clin Pharmacol Ther 2011; 89: 259-67

21. Huang SM, Rowland M. The role of physiologically based pharmacokinetic modeling in regulatory review. Clin Pharmacol Ther 2012; 91: 542-49

22. Rowland M, Balant L, Peck C. Physiologically based pharmacokinetics in drug development and regulatory science: a workshop report (Georgetown University, Washington, DC, May 29-30, 2002). AAPS Pharm Sci 2004; 6: E6-12

23. Bjorkman S. Prediction of drug disposition in infants and children by means of physiologically based pharmacokinetic (PBPK) modelling: theophylline and midazolam as model drugs. Br J Clin Pharmacol 2006; 59: 691-704

24. Edginton AN, Schmitt W, Willmann S. Development and evaluation of a generic physiologically based pharmacokinetic model in children. Clin Pharmacokinet 2006; 45: 1013-34

25. Yang F, Tong X, McCarver DG, et al. Population based analysis of methadone distribution and metabolism using an age-dependent physiologically based pharmacokinetic model. J Pharmacokinet Pharmacodyn 2006; 33: 485-518

26. Alemzadeh R, Hoffmann RG, Dasgupta M, et al. Development of optimal kids insulin dosing system formulas for young children with type 1 diabetes mellitus. Diabetes Technol Ther 2012;14:418-22

27. Bouillon-Pichault M, Jullien V, Bazzoli C, et al. Pharmacokinetic design optimization in children and estimation of maturation parameters: example of cytochrome P450 3A4. J Pharmacokinet Pharmacodyn 2011; 38: 25-40 
28. Ogungbenro K, Matthews I, Looby M, et al. Population pharmacokinetics and optimal design of paediatric studies for famciclovir. Br J Clin Pharmacol 2009; 68: 546-60

29. Perdaems N, Blasco H, Vinson C, et al. Predictions of metabolic drug-drug interactions using physiologically based modelling. Clin Pharmacokinet 2010; 49: 239-58

30. Chenel M, Bouzom F, Aarons L, Ogungbenro K. Drug-drug interaction predictions with PBPK models and optimal multiresponse sampling time designs: application to midazolam and a phase I compound. Part 1: comparison of uniresponse and multiresponse designs using PopDes. J Pharmacokinet Pharmacodyn. 2008; 35:635-59.a

31. Ahn JE, Karlsson MO, Dunne A, et al. Likelihood based approaches to handling data below the quantification limit using NONMEM VI. J Pharmacokinet Pharmacodyn 2008; 35: 401-21

32. Samson A, Lavielle M, Mentré F. Extension of the SAEM algorithm to left-censored data in nonlinear mixed-effects model: application to HIV dynamics model. Comput Stat Data Anal 2006; 51: 1562-74

33. Rochon J. Application of GEE procedures for sample size calculations in repeated measures experiments. Stat Med 1998; 17: 1643-58

34. Ogungbenro K, Aarons L, Graham G. Sample size calculations based on generalized estimating equations for population pharmacokinetic experiments. J Biopharm Stat 2006; 16: 135-50

35. Rodgers T, Leahy D, Rowland M. Physiologically based pharmacokinetic modelling 1: predicting the tissue distribution of moderate-to-strong bases. J Pharm Sci 2005; 94: 1259-76

36. Johnson TN, Rostami-Hodjegan A. Resurgence in the use of physiologically based pharmacokinetic models in pediatric clinical pharmacology: parallel shift in incorporating the knowledge of biological elements and increased applicability to drug development and clinical practice. Paediatr Anaesth 2011; 21: 291-301

37. Beal SL, Sheiner LB. NONMEM users guide. San Francisco: University of California; 1992

38. Wang Y. Derivation of various NONMEM estimation methods. J Pharmacokinet Pharmacodyn 2007; 34: 575-93

39. Bertrand J, Comets E, Mentré F. Comparison of model-based tests and selection strategies to detect genetic polymorphisms influencing pharmacokinetic parameters. J Biopharm Stat 2008; 18: 1084-1102

40. Brendel K, Comets E, Laffont C, et al. Metrics for external model evaluation with an application to the population pharmacokinetics of gliclazide. Pharm Res 2006; 23: 2036-49

41. Retout S, Comets E, Samson A, et al. Design in nonlinear mixed effects models: Optimization using the Federov-Wynn algorithm and power of the Wald test for binary covariates. Stat Med 2007; 26: 5162-79

42. Dumont C, Chenel M, Mentré F. Design evaluation in nonlinear mixed effect models: influence of covariance between random effects [abstract no. 2158]. Population Approach Group in Europe (PAGE); 7-10 June 2011; Athens. http://www.page-meeting.org/?abstract=2158. Accessed 30 Oct 2012

43. Dumont $\mathrm{C}$, Chenel M, Mentré F. Influence of covariance between random effects in design for nonlinear mixed effect models with an illustration in paediatric pharmacokinetics. J Biopharm Stat. In press 
44. Dubois A, Bertrand J, Mentré F. Mathematical expressions of the pharmacokinetic and pharmacodynamic models implemented in the PFIM software.. http://www.pfim.biostat.fr/PFIM_PKPD_library.pdf Accessed 2012 Nov 5

45. Sölkner J. Choice of optimality criteria for the design of crossbreeding experiments. J Anim Sci 1993; 71: 2867-73

46. Vila JP, Gauchi JP. Optimal designs based on exact confidence regions for parameter estimation of a nonlinear regression model. J Stat Plan Inference 2007; 137: 2935-53

47. Mentré F, Nyberg J, Ogungbenro K, et al. Comparison of results of the different software for design evaluation in population pharmacokinetics and pharmacodynamics [abstract no. 2066]. Population Approach Group in Europe (PAGE); 7-10 June 2011; Athens. http://www.pagemeeting.org/?abstract $=2066$. Accessed 30 Oct 2012

48. Dokoumetzidis A. Lumping of compartments [abstract no. 2637]. Population Approach Group in Europe (PAGE); 5-8 June 2012; Venice. http://www.page-meeting.org/?abstract=2637. Accessed 30 Oct 2012

49. Foo LK, Duffull S. Adaptive optimal design for bridging studies with an application to population pharmacokinetic studies. Pharm Res. 2012; 29: 1530-43

50. Strougo A, Eissing T, Yassen A, et al. First dose in children: physiological insights into pharmacokinetic scaling approaches and their implications in paediatric drug development. $\mathrm{J}$ Pharmacokinet Pharmacodyn 2012; 39: 195-203 
Table 1. Investigated scenarios with the number of individual sampling times over each design domain and potential constraints; the sampling times are the same for all children and are among 0.1 , $0.2,0.4,0.6,0.8,1,1.3,1.6,1.8,2,2.5,3,4,5,6,7,8,9,10,12,16$ and $24 \mathrm{~h}$

\begin{tabular}{|c|c|c|c|}
\hline Design & $\begin{array}{l}\text { Number of } \\
\text { sampling } \\
\text { times }\end{array}$ & $\begin{array}{l}\text { Design domain } \\
(\text { in } \mathrm{h})^{\mathrm{a}}\end{array}$ & $\begin{array}{l}\text { Constraint of no sampling time between } 0.3 \\
\text { and } 1.5 \mathrm{~h}\end{array}$ \\
\hline$\Xi_{\text {4pts_24h }}$ & 4 & {$[0.1 ; 24]$} & No \\
\hline$\Xi_{5 \mathrm{pts} \_24 \mathrm{~h}}$ & 5 & {$[0.1 ; 24]$} & No \\
\hline$\Xi_{6 \mathrm{pts} \_24 \mathrm{~h}}$ & 6 & {$[0.1 ; 24]$} & No \\
\hline$\Xi_{4 \mathrm{pts} \_5 \mathrm{~h}}$ & 4 & {$[0.1 ; 5]$} & Yes \\
\hline \multirow[t]{2}{*}{$\Xi_{3 p t s \_5 h \_1 p t \_6 h}$} & 3 & {$[0.1 ; 5]$} & Yes \\
\hline & 1 & $\{6\}$ & \\
\hline \multirow[t]{2}{*}{$\Xi_{\text {3pts_5h_1pt_8h }}$} & 3 & {$[0.1 ; 5]$} & Yes \\
\hline & 1 & $\{8\}$ & \\
\hline \multirow[t]{2}{*}{$\Xi_{3 p t s \_5 h_{-} 1 p t \_10 \mathrm{~h}}$} & 3 & {$[0.1 ; 5]$} & Yes \\
\hline & 1 & $\{10\}$ & \\
\hline \multirow[t]{2}{*}{$\Xi_{\text {3pts_5h_1pt_24h }}$} & 3 & {$[0.1 ; 5]$} & Yes \\
\hline & 1 & $\{24\}$ & \\
\hline \multirow[t]{2}{*}{$\Xi_{4 \mathrm{pts} \_5 \mathrm{~h}_{-} 1 \mathrm{pt} \_10 \mathrm{~h}}$} & 4 & {$[0.1 ; 5]$} & Yes \\
\hline & 1 & $\{10\}$ & \\
\hline \multirow[t]{2}{*}{$\Xi_{5 \mathrm{pts} \_5 \mathrm{~h} \_1 \mathrm{pt} \_10 \mathrm{~h}}$} & 5 & {$[0.1 ; 5]$} & Yes \\
\hline & 1 & $\{10\}$ & \\
\hline
\end{tabular}

${ }^{\mathrm{a}}$ The times in the brackets indicate the sampling time interval for the design, with the additional sampling time shown in the braces 
Table 2. Parameter estimates and corresponding relative standard error of the joint parent and metabolite population pharmacokinetic model

\begin{tabular}{|c|c|}
\hline Parameters (units) & Parameter estimates (RSE \%) \\
\hline $\mathrm{CL}_{\mathrm{P}}(\mathrm{L} / \mathrm{h} / \mathrm{kg})$ & $0.61(2.6)$ \\
\hline $\mathrm{CL}_{\mathrm{PM}}(\mathrm{L} / \mathrm{h} / \mathrm{kg})$ & $0.11(7.9)$ \\
\hline $\mathrm{V}_{1}(\mathrm{~L} / \mathrm{kg})$ & $0.97(1.4)$ \\
\hline $\mathrm{Q}_{2}(\mathrm{~L} / \mathrm{h} / \mathrm{kg})$ & $0.12(24)$ \\
\hline $\mathrm{V}_{2}(\mathrm{~L} / \mathrm{kg})$ & $0.41(16)$ \\
\hline $\mathrm{Q}_{3}(\mathrm{~L} / \mathrm{h} / \mathrm{kg})$ & $0.69(3.5)$ \\
\hline $\mathrm{V}_{3}(\mathrm{~L} / \mathrm{kg})$ & $0.87(6.4)$ \\
\hline $\mathrm{CL}_{\mathrm{M}}(\mathrm{L} / \mathrm{h} / \mathrm{kg})$ & $0.91(3.0)$ \\
\hline$\omega^{2} \mathrm{CL}_{\mathrm{P}}$ & $0.25(6.1)$ \\
\hline$\omega^{2} \mathrm{CL}_{\mathrm{PM}}$ & $1.4(8.1)$ \\
\hline$\omega^{2} v_{1}$ & $0.070(10)$ \\
\hline$\omega^{2} \mathrm{CL}_{\mathrm{M}}$ & $0.27(6.8)$ \\
\hline$\omega_{\mathrm{CL}_{\mathrm{p}}, \mathrm{v}_{1}}$ & $0.045(14)$ \\
\hline$\omega_{\mathrm{CL}_{\mathrm{P}}}, \mathrm{CL}_{\mathrm{PM}}$ & $0.036(85)$ \\
\hline$\omega_{\mathrm{V}_{1}, \mathrm{CL}_{\mathrm{PM}}}$ & $0.024(59)$ \\
\hline$\omega_{\mathrm{CL}_{\mathrm{p}}, \mathrm{CL}_{\mathrm{M}}}$ & $0.091(15)$ \\
\hline$\omega_{\mathrm{V}_{1}}, \mathrm{CL}_{\mathrm{M}}$ & $0.083(9.2)$ \\
\hline$\omega_{\mathrm{CL}_{\mathrm{PM}}, \mathrm{CL}_{\mathrm{M}}}$ & $-0.045(63)$ \\
\hline$\sigma_{\text {interP }}(\mu \mathrm{g} / \mathrm{L})$ & $0.072(18)$ \\
\hline$\sigma_{\text {slopeP }}$ & $0.16(4.8)$ \\
\hline
\end{tabular}


$\sigma_{\text {inter } P}$ and $\sigma_{\text {inter } M}$ additive error for the parent drug and its active metabolite, respectively,$\sigma_{\text {slope } P}$ and $\sigma_{\text {slopem }}$ proportional parts of the residual error models for the parent drug and its active metabolite, respectively, $\omega^{2}$ variance, $C L_{M}$ elimination clearance of the metabolite, $C L_{P}$ elimination clearance of the parent drug, $C L_{P M}$ formation clearance of the metabolite from the parent drug, $Q_{2}$ and $Q_{3}$ are the inter-compartmental clearances from compartment 1 to compartment 2 and from compartment 1 to compartment 3, respectively, RSE relative standard error, $V_{i}$ volume of the $\mathrm{i}^{\text {th }}$ compartment 
Table 3. Results of optimization by PFIM for three designs: four, five and six sampling times over 24 $\mathrm{h}$ after dose injection without any constraints

\begin{tabular}{|c|c|c|c|}
\hline Parameters & $\Xi_{4 \text { pts_24h }}$ & $\Xi_{5 \mathrm{pts} \_24 \mathrm{~h}}$ & $\Xi_{6 \mathrm{pts} \_24 \mathrm{~h}}$ \\
\hline Optimal sampling times (h) & $0.2,2,8,24$ & $0.1,1.6,5,12,24$ & $0.1,0.8,2.5,7,16,24$ \\
\hline$(\text { Determinant })^{1 / 16}$ & 1640 & 2230 & 2567 \\
\hline \multicolumn{4}{|l|}{ Predicted RSE (\%) } \\
\hline $\mathrm{CL}_{\mathrm{P}}$ & 5.6 & 5.6 & 5.6 \\
\hline $\mathrm{CL}_{\mathrm{PM}}$ & 13 & 13 & 13 \\
\hline $\mathrm{V}_{1}$ & 3.7 & 3.4 & 3.4 \\
\hline $\mathrm{Q}_{2}$ & $213^{\mathrm{a}}$ & $74^{\mathrm{a}}$ & $57^{\mathrm{a}}$ \\
\hline $\mathrm{V}_{2}$ & $139^{\mathrm{a}}$ & $50^{\mathrm{a}}$ & $36^{\mathrm{a}}$ \\
\hline $\mathrm{Q}_{3}$ & 30 & 9.3 & 8.7 \\
\hline $\mathrm{V}_{3}$ & $62^{\mathrm{a}}$ & 23 & 18 \\
\hline $\mathrm{CL}_{\mathrm{M}}$ & 6.4 & 6.3 & 6.1 \\
\hline$\omega^{2} \mathrm{CL}_{\mathrm{P}}$ & 16 & 16 & 16 \\
\hline$\omega^{2} \mathrm{CL}_{\mathrm{PM}}$ & 16 & 16 & 16 \\
\hline$\omega^{2} v_{1}$ & 21 & 20 & 20 \\
\hline$\omega^{2} \mathrm{CL}_{\mathrm{M}}$ & 17 & 17 & 17 \\
\hline$\sigma_{\text {interP }}(\mu \mathrm{g} / \mathrm{L})$ & 11 & 10 & 9.6 \\
\hline$\sigma_{\text {slopeP }}$ & 7.0 & 5.7 & 5.0 \\
\hline$\sigma_{\text {interM }}(\mu \mathrm{g} / \mathrm{L})$ & 9.9 & 9.4 & 8.8 \\
\hline$\sigma_{\text {slopeM }}$ & 14 & 8.7 & 7.4 \\
\hline \multicolumn{4}{|c|}{$\begin{array}{l}\sigma_{\text {inter } P} \text { and } \sigma_{\text {inter }} \text { additive error for the parent drug and its active metabolite, respectively, } \sigma_{\text {slope }} \text { and } \\
\sigma_{\text {slopem }} \text { proportional parts of the residual error models for the parent drug and its active metabolite, } \\
\text { respectively, } \omega^{2} \text { variance, } C L_{M} \text { elimination clearance of the metabolite, } C L_{P} \text { elimination clearance of } \\
\text { the parent drug, } C L_{P M} \text { formation clearance of the metabolite from the parent drug, } Q_{2} \text { and } Q_{3} \text { are the } \\
\text { inter-compartmental clearances from compartment } 1 \text { to compartment } 2 \text { and from compartment } 1 \text { to } \\
\text { compartment } 3 \text {, respectively, } R S E \text { relative standard error, } V_{i} \text { volume of the } \mathrm{i}^{\text {th }} \text { compartment }\end{array}$} \\
\hline
\end{tabular}


Table 4. Results of optimization by PFIM for five designs: four sampling times increasing the last time (i.e. 5, 6, 8, 10 and $24 \mathrm{~h}$ after dose) and with no pharmacokinetic samples between 20 and 90 min

\begin{tabular}{llllll}
\hline Parameters & $\Xi_{\text {4pt_5h }}$ & $\Xi_{\text {3pt__5h_1pt_6h }}$ & $\Xi_{\text {3pts_5h_1pt_8h }}$ & $\Xi_{\text {3pts_5h_1pt_10h }}$ & $\Xi_{\text {3pt_5h_1pt_24h }}$ \\
\hline Optimal sampling times (h) & $0.1,1.6,3,5$ & $0.1,1.6,4,6$ & $0.1,1.6,4,8$ & $0.1,1.8,5,10$ & $0.1,1.8,5,24$ \\
(Determinant) $^{1 / 16}$ & 322 & 420 & 603 & 774 & 1,583 \\
Predicted RSE (\%) & & & & \\
CL & & $109^{\mathrm{a}}$ & 23 & 8.6 & 5.8 \\
$\mathrm{~V}_{1}$ & $343^{\mathrm{a}}$ & 3.4 & 3.4 & 3.4 & 3.4 \\
$\mathrm{CL}_{\mathrm{PM}}$ & 3.5 & $234^{\mathrm{a}}$ & $53^{\mathrm{a}}$ & 20 & 13 \\
$\mathrm{CL}_{\mathrm{M}}$ & $710^{\mathrm{a}}$ & $234^{\mathrm{a}}$ & $51^{\mathrm{a}}$ & 16 & 6.6 \\
\hline
\end{tabular}

$C L_{M}$ elimination clearance of the metabolite, $C L_{P}$ elimination clearance of the parent drug, $C L_{P M}$ formation clearance of the metabolite from the parent drug, $R S E$ relative standard error, $V_{l}$ volume of the central compartment for the parent drug

${ }^{a}$ RSE greater than $30 \%$ 
Table 5. Results of optimization by PFIM for three designs: three, four and five sampling times until 5 $\mathrm{h}$ and one additional time $10 \mathrm{~h}$ after dose, with no pharmacokinetic samples between 20 and $90 \mathrm{~min}$

\begin{tabular}{|c|c|c|c|}
\hline Parameters & $\Xi_{\text {3pts_5h_1pt_10h }}$ & $\Xi_{4 \mathrm{pts} \_5 \mathrm{~h} \_1 \mathrm{pt} \_10 \mathrm{~h}}$ & $\Xi_{5 \mathrm{pts} \_5 \mathrm{~h} \_1 \mathrm{pt} \_10 \mathrm{~h}}$ \\
\hline $\begin{array}{l}\text { Optimal sampling times } \\
\text { (h) }\end{array}$ & $0.1,1.8,5,10$ & $0.1,1.6,1.8,5,10$ & $0.1,1.6,1.8,4,5,10$ \\
\hline$(\text { Determinant })^{1 / 16}$ & 774 & 951 & 1,065 \\
\hline \multicolumn{4}{|l|}{ Predicted RSE (\%) } \\
\hline $\mathrm{CL}_{\mathrm{P}}$ & 8.6 & 8.3 & 8.0 \\
\hline $\mathrm{V}_{1}$ & 3.4 & 3.4 & 3.4 \\
\hline $\mathrm{CL}_{\mathrm{PM}}$ & 20 & 19 & 19 \\
\hline $\mathrm{CL}_{\mathrm{M}}$ & 16 & 15 & 14 \\
\hline
\end{tabular}

$C L_{M}$ elimination clearance of the metabolite, $C L_{P}$ elimination clearance of the parent drug, $C L_{P M}$ formation clearance of the metabolite from the parent drug, $R S E$ relative standard error, $V_{l}$ volume of the central compartment for the parent drug 
Table 6. Proportion (\%) of children with concentrations below the lower limit of quantification for the parent drug and for the metabolite, obtained by simulation using the population joint parentmetabolite pharmacokinetic model in $\mathrm{R}$, at the sampling times of the designs $\Xi_{3 \mathrm{pts} \_ \text {5h_1pt_10h }}$ or $\Xi_{3 p t s \_5 h \_1 p t \_24 h}($ i.e. $0.1,1.8,5$ and 10 or $24 \mathrm{~h}$ after dose administration)

\begin{tabular}{llllll}
\hline Compound & $0.1 \mathrm{~h}$ & $1.8 \mathrm{~h}$ & $5 \mathrm{~h}$ & $10 \mathrm{~h}$ & $24 \mathrm{~h}$ \\
\hline Parent & 0.00 & 0.00 & 0.60 & 8.4 & 75 \\
Metabolite & 34 & 3.3 & 9.7 & 33 & 92 \\
\hline
\end{tabular}




\section{Figure captions}

Fig. 1. Simulated concentration-time profiles for the parent drug $(\mathbf{a}, \mathbf{b})$ and for its active metabolite (c, d) in Cartesian scale $(\mathbf{a}, \mathbf{c})$ and in semi-log scale $(\mathbf{b}, \mathbf{d})$ in children using SIMCYP ${ }^{\circledR}$. The solid lines correspond to the median of the observations and the dots represent individual data

Fig.2. Structural pharmacokinetic model of the joint parent and metabolite population pharmacokinetic model with four compartments. $C L_{M}$ elimination clearance of the metabolite, $C L_{P}$ elimination clearance of the parent drug, $C L_{P M}$ formation clearance of the metabolite from the parent drug, $Q_{2}$ and $Q_{3}$ are the inter-compartmental clearances from compartment 1 to compartment 2 and from compartment 1 to compartment 3 , respectively, $V_{i}$ volume of the $\mathrm{i}^{\text {th }}$ compartment

Fig. 3. Goodness-of-fit plots for the joint parent and metabolite pharmacokinetic model. SIMCYP ${ }^{\circledR}$ data (called dependent variable) vs. individual predictions (a, c) and normalized prediction distribution error vs. time (b, d) for the parent drug $(\mathbf{a}, \mathbf{b})$ and its active metabolite $(\mathbf{c}, \mathbf{d}) . D V$ dependent variable, IPRED individual prediction, NPDE normalized prediction distribution error

Fig. 4. Efficiency (defined as ratio of (determinant) ${ }^{1 / \mathrm{P}}$ of the tested design to the chosen design $\Xi_{3 p t s \_5}$ h_lpt_10h $\left._{1}\right)$. The horizontal line is the unit line to see the gain or the loss of efficiency of each design compared to the optimal design $\Xi_{3 \text { pts__h__lpt_10h }}$

Fig. 5. Relative standard error (\%) showing the comparison between evaluation of the $\Xi_{3 \mathrm{pts} \_ \text {h__1pt_10h }}$

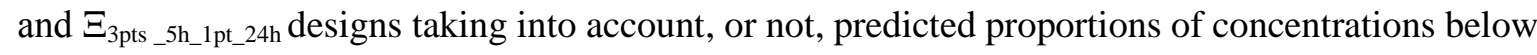
the lower limit of quantification. $C L_{M}$ elimination clearance of the metabolite, $C L_{P}$ elimination clearance of the parent drug, $C L_{P M}$ formation clearance of the metabolite from the parent drug, $B L Q$ below the limit of quantification, $R S E$ relative standard error, $V_{l}$ volume of the central compartment for the parent drug 

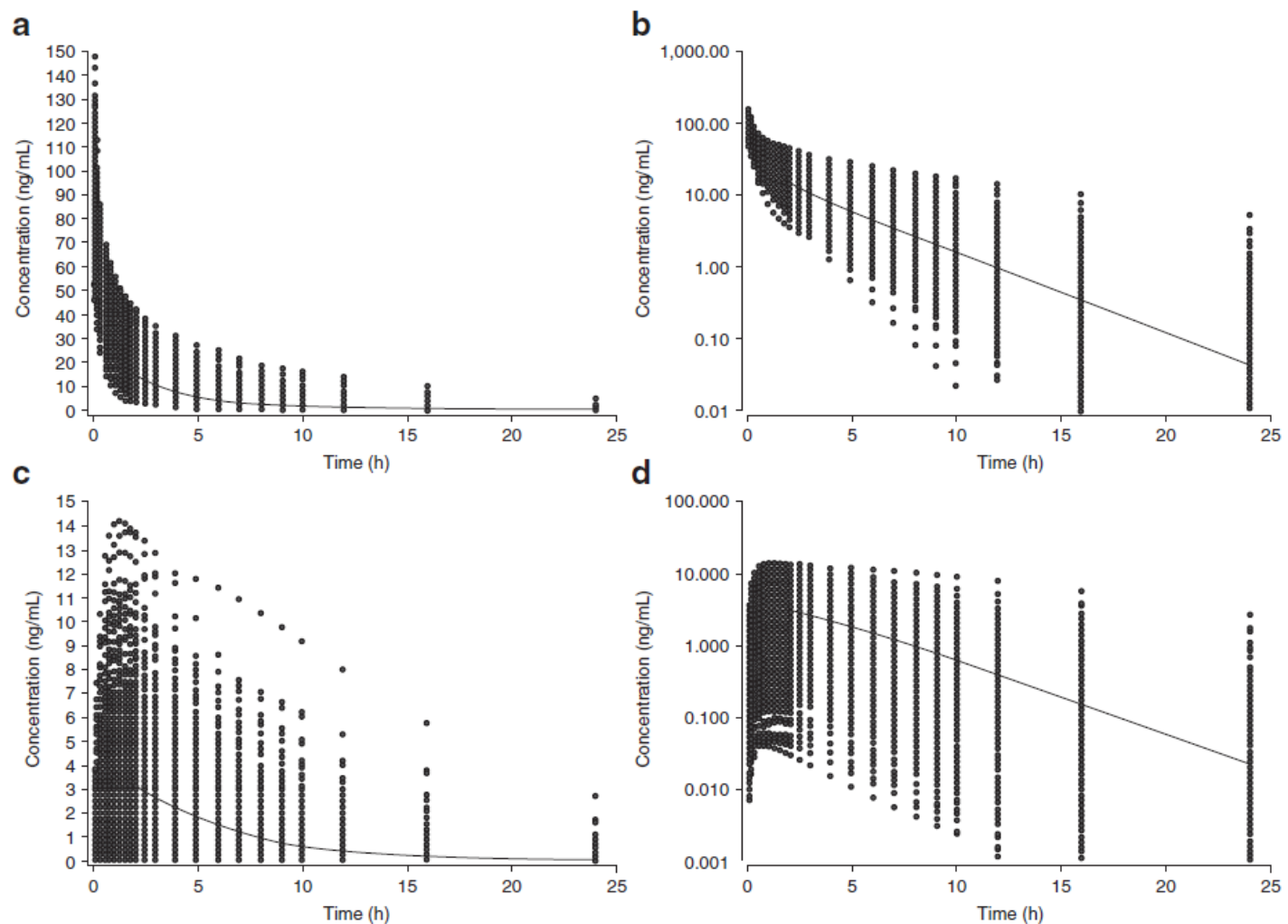

Figure 1 


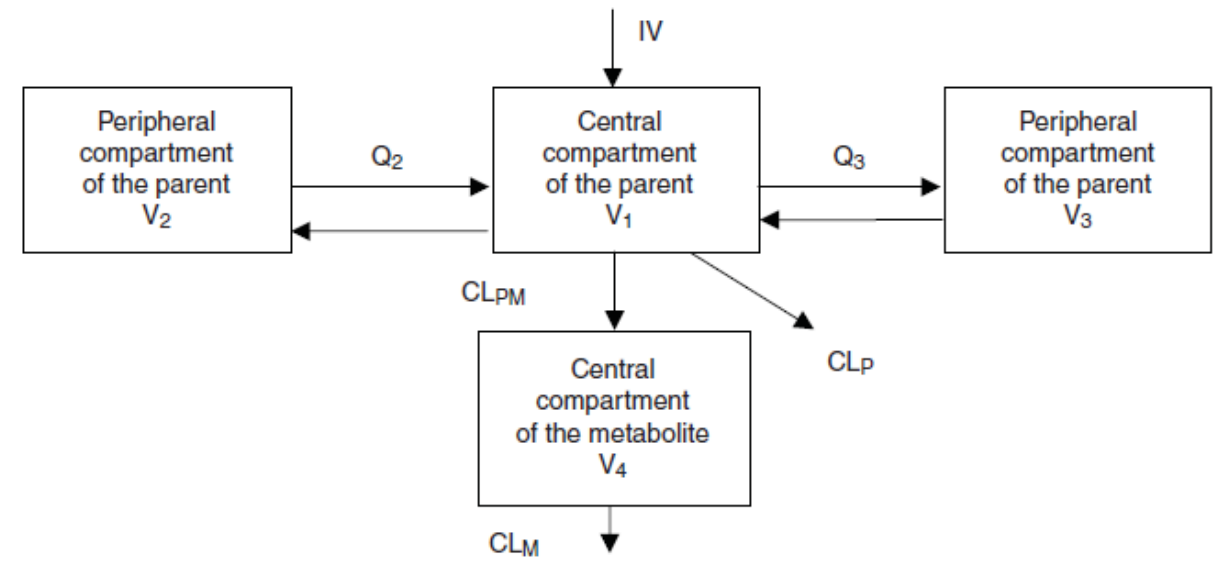

Figure 2 
a

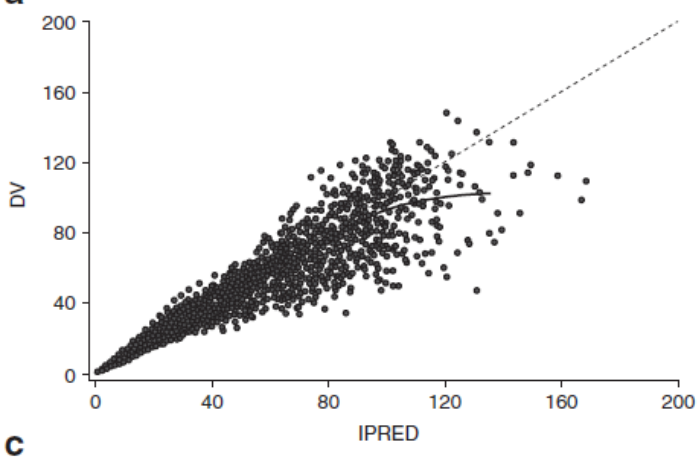

C

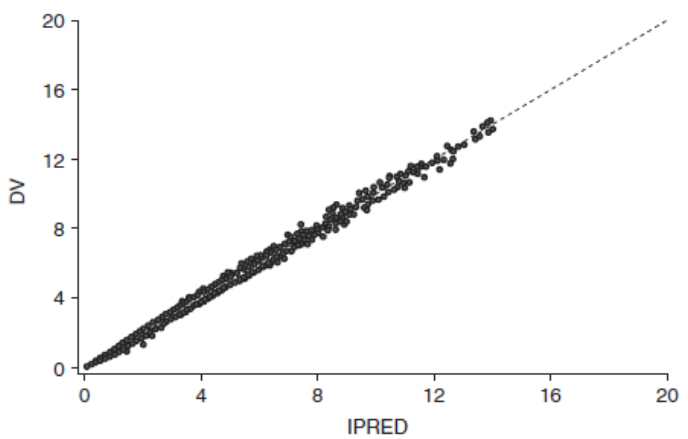

b
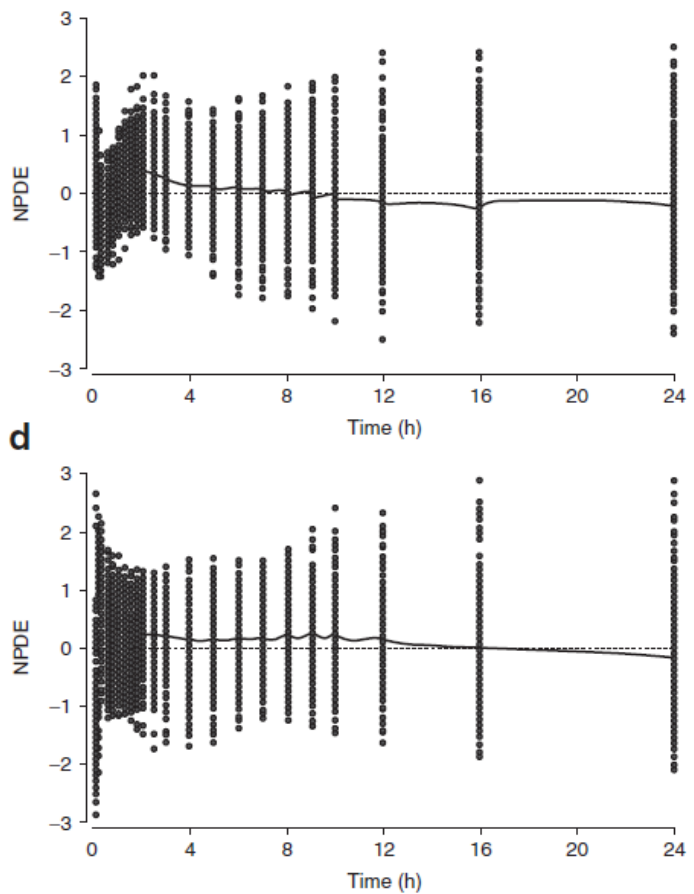

Figure 3 


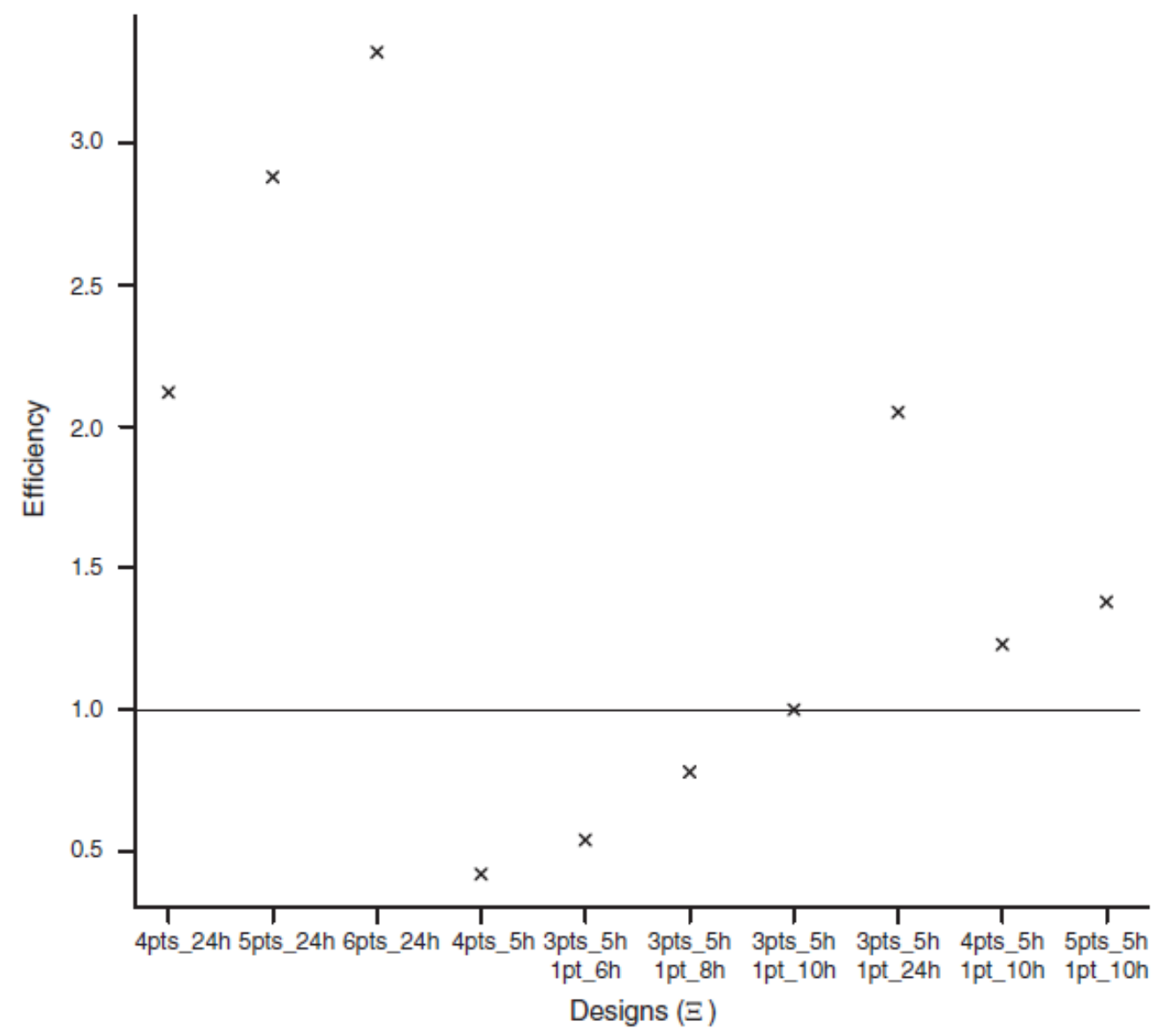

Figure 4 


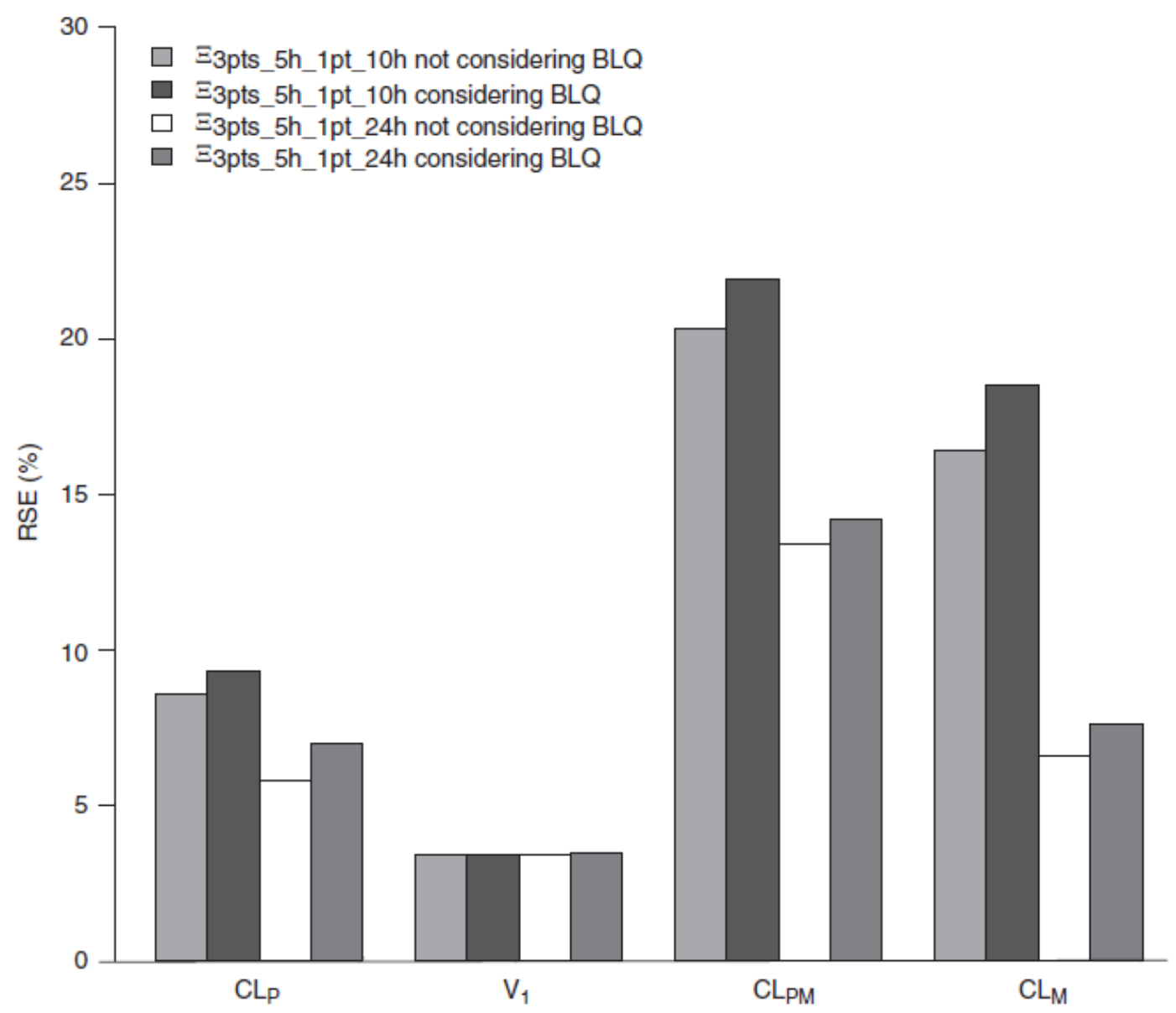

Figure 5 